\title{
Time scale analysis for fluidized bed melt granulation I: granule-granule and granule-droplet collision rates
}

\author{
Kel W. Chua ${ }^{\mathrm{a}}$, Yassir T. Makkawi ${ }^{\mathrm{b}, *}$, Michael J. Hounslow ${ }^{\mathrm{a}}$ \\ a Particle Products Group, Department of Chemical and Process Engineering, The \\ University of Sheffield, Sheffield S1 3JD, United Kingdom \\ ${ }^{b}$ Chemical Engineering and Applied Chemistry, School of Engineering and Applied \\ Science, Aston University, Birmingham B4 7ET, United Kingdom
}

\section{Abstract}

Fluidized Bed Spray Granulators (FBMG) are widely used in the process industry for particle size growth; a desirable feature in many products, such as granulated food and medical tablets. In this paper, the first in a series of four discussing the rate of various microscopic events occurring in FBMG, theoretical analysis coupled with CFD simulations have been used to predict granule-granule and droplet-granule collision time scales. The granule-granule collision time scale was derived from principles of Kinetic Theory of Granular Flow (KTGF). For the droplet-granule collisions, two limiting models were derived; one is for the case of fast droplet velocity, were the granule velocity is considerable lower than that of the droplet (ballistic model) and another for the case were the droplet is traveling with a velocity similar to the velocity of the granules. The hydrodynamic parameters used in the solution of the above models were obtained from the CFD predictions for a typical spray fluidized bed system. The granule-granule collision rate within an identified spray zone was found to fall approximately within the range of $10^{-2}$ and $10^{-3} \mathrm{~s}$, while the droplet-granule collision was found to be much faster, however, slowing rapidly (exponentially) when moving away from the spray nozzle tip. Such information, together with the time scale analysis of droplet solidification and spreading, discussed in part II and III of this study, are useful for probability analysis of the various event occurring during a granulation process, which then lead to be better qualitative and, in part IV, quantitative prediction of the aggregation rate.

Keywords: fluidization; granulation, CFD; collisions, particle processing; particle technology

\footnotetext{
* Corresponding author. +44 (0)121 204 3398; email: y.makkawi@aston.ac.uk
} 


\section{Introduction}

Fluidized bed melt granulation (FBMG) is a widely used process for industrial production of enlarged granules such as in pharmaceutical, detergents and food industries. FBMG has substantial advantages over other granulation methods as it occurs in a one single process and is particular suitable for the production of granules with high porosity and uniform size distribution. The process is carried out in a fluid bed fitted with liquid spray nozzle, where a melt liquid binder is sprayed onto a particulate suspension of fine powder to produce larger granules. The binder solidifies on the powder and since granule-granule collisions are frequent, individual granules will often be bound together by the solidifying binder. Depending on the type of binder and operating conditions used, the liquid bridge forming between any two granules will either solidify by cooling or dry by heating to form a granule. This simple physical process is highly difficult to predict due to the poor understating of the rate of a number of events leading to formation of a granule.

\section{Background and motivations of the study}

Recently, a number of models, focused on granule growth and heat and mass transfer in spray fluidized bed, have been based on droplet deposition and rapid granules coalescence processes within the active spray zone area (Schaafsma et al. 2006, Heinrich et al., 2006). This concept was shown to be physically plausible in describing and predicting many aspects of interest in spray fluidized bed granulators.

In predicting the evolution of granule size distribution using Population Balance Modeling (PBM), Tan et. al. (2004) suggested that the aggregation rate constant required for the solution of PBM can be determined in terms of various operating factors (such as wetability, granule velocity, binder type and concentration) and an unknown success factor for aggregation. Our understanding of the underlying physical principles of the process suggest that the success factor for aggregation depend on the rates of four major events occurring at the granule level. These are described schematically in 
Fig. 1. Each one of these events occurs at a different time scale and contributes in one way or another to the overall aggregation process as described below:

1. The droplet-granule collision rate determines the number of droplet deposited onto granules per unit time, and,

2. The binder spreading or wetting rate determines the time required for droplet to spread to its equilibrium position and hence, the extent of binder coverage on a given granule surface, and,

3. The granule-granule collision rate determines the number of successful wet granules contacts with respect to solidification and spreading time, and

4. The droplet solidification rate determines the life span of a hot molten binder droplet before eventually solidifying on the granule surface.

Two colliding granules will only form an aggregate if at least one of them is wetted and they collide at the point where the binder is still in a liquid state. Therefore, the probability of forming new granules is directly related to the rates of these four events. In fluidized bed granulation process, it is widely believed that the time scales for granule-granule collision are short, in the range of microseconds, the solidification process is relatively slower, in the range of millisecond. However, these remain just speculations and therefore, an accurate model to describe the time scale of each event is an important step towards full theoretical prediction of granule growth in a spray fluidized bed granulator.

In an effort to shed light on the probable scenarios in FBMG, Tan et al. (2006) suggested that all binder droplets would be consumed for aggregation because granulegranule collision time scale is much shorter than binder spreading and solidification times. However, this view was not supported with numerical or experimental evidence. In fact, the time scale analysis presented in this series, depict a more complex set of scenarios. In a different approach to understanding microscopic events in FBMG, Thielmann et al. (2008) recently used Population Balance Modeling (PBM) coupled with Stoke analysis to estimate the probability of coalescence of two colliding granules and subsequently estimate the final granule size distribution. Their simulations show that 
there is a strong sensitivity to the granules collision velocity and the binder drying kinetics. Goldschmidt et al. (2001) developed a method to extract data on granulegranule collision time scale in FBMG using the kinetic theory of granular flow (KTGF). While this model yielded valuable information when applied to PBM (Tan et al., 2004) its application to predicting the dynamics of granule-granule collision for various FBMG operating conditions was not pursued.

In this series of papers, focus is made on the time scale analysis of the followings:

i) Granule-granule and granule-droplet collisions (this study)

ii) Droplet spreading (paper II),

iii) Droplet solidification (paper III)

iv) Aggregation rate (paper IV)

Direct experimental measurement of the time scale of these events in actual FBMG is extremely difficult, mainly due to the limitation in spatial resolutions and the very short and transient nature of these events. Therefore, it is the overall aim of this series of papers to present a theoretical approach to estimate the magnitude of these time scales and to validate the theoretical approach with experimental measurements at larger length-, and longer time-, scales.

A summary of the various time scales studied in this series is shown in Fig. 2. In series II and III we will discuss in details the models used for predicting the spreading and solidification rates and the experimental procedure used in validating these models. In this first paper, we will focus on the granule-granule collision rate, or times $\left(\tau_{s-s}\right)$ and droplet-granule collision rate, or times $\left(\tau_{D-s}\right)$ only. The time scale of these collisions will be obtained from theoretical analysis with the aid of hydrodynamic data obtained from Computational Fluid Dynamic (CFD). For this purpose, the widely used CFD package Fluent will be used to extract two important hydrodynamic parameters, namely, the granule concentration and granular temperature. Since in FBMG, binder droplets are brought into contact with the granules at the upper region of the expanded bed, in what we referred to as spray zone, a localized analysis based on spray zone concept is 
performed to quantify the collision rates. The spray zone boundaries will be obtained from analysis of the droplet deposition and consumption downstream of the spray nozzle.

\section{CFD simulation of fluidized bed}

In this work an Euler-Euler approach of the two-fluid model was used to simulate the flow hydrodynamics of the solid and gas interactions in the spray fluidized bed granulator. The main purpose of the simulation was to extract useful quantitative information on the spatial variations of the granules concentration and granular temperature with special focus on the spray zone. The granular temperature, which is the measure of random velocity fluctuations of the granules according to the Kinetic Theory of Granular Flow (KTGF), was used along with the granules concentration in calculating the granule-granule and granule-droplet collision rates.

\subsection{Model formulations}

This model treats the two phases, gas and solid, as interpenetrating continuum. The following continuity, conservation of momentum and energy equations are solved for the gas and solid phases:

Continuity equation:

$$
\frac{\partial}{\partial t}\left(\varepsilon_{i} \rho_{i}\right)+\nabla \cdot\left(\varepsilon_{i} \rho_{i} \vec{u}_{i}\right)=0 \quad(i=\text { gas, solids })
$$

Gas momentum equation:

$$
\frac{\partial}{\partial t}\left(\varepsilon_{g} \rho_{g} \vec{u}_{g}\right)+\nabla \cdot\left(\varepsilon_{g} \rho_{g} \vec{u}_{g} \vec{u}_{g}\right)=\nabla \cdot \bar{\tau}_{g}-\varepsilon_{g} \nabla p+\varepsilon_{g} \rho_{g} \overrightarrow{\mathbf{g}}-\beta\left(\vec{u}_{g}-\vec{u}_{s}\right)
$$

Solid momentum equation:

$$
\frac{\partial}{\partial t}\left(\varepsilon_{s} \rho_{s} \vec{u}_{s}\right)+\nabla \cdot\left(\varepsilon_{s} \rho_{s} \vec{u}_{s} \vec{u}_{s}\right)=\nabla \cdot \stackrel{\bar{\tau}_{s}}{-}-\nabla p_{s}^{*}-\varepsilon_{s} \nabla p+\varepsilon_{s} \rho_{s} \overrightarrow{\mathbf{g}}-\beta\left(\vec{u}_{s}-\vec{u}_{g}\right)
$$

Granular energy equation:

$$
\frac{3}{2}\left[\frac{\partial}{\partial t}\left(\varepsilon_{s} \rho_{s} \theta\right)+\nabla \cdot\left(\varepsilon_{s} \rho_{s} \theta\right) \vec{u}_{s}\right]=\left(-p_{s}^{*} \gamma+\bar{\tau}_{s}\right): \nabla \vec{u}_{s}+\nabla \cdot\left(k_{s} \nabla \theta\right)-\gamma_{s}
$$


The closure equations for the drag coefficient $(\beta)$, gas and solid shear stresses $\left(\overline{\bar{\tau}}_{g}, \overline{\bar{\tau}}_{s}\right)$, solid normal pressures $\left(p_{s}^{*}\right)$, effective thermal conductivity of the solid phase $\left(k_{s}\right)$ and the granular energy dissipation $\left(\gamma_{s}\right)$ are all summarized in Table. 1. Further details on the model formulations and optional closure equations can be found in Fluent documentation (Fluent 6.3).

Within this framework the granular temperature is of particular importance to the present work since, as we will see, it can be related directly to the frequency of collisions. We refer to the granular temperature, $\theta$, as the mean square fluctuation in velocity of granules, $C$, as follows:

$\theta=\left\langle C^{2}\right\rangle$

and to the mixture granular temperature, $\theta_{s}$, as:

$\theta_{s}=\frac{\pi}{6} \rho_{s} d_{s}^{3} \theta$

where $\rho_{s}$ and $d_{s}$ are the solid density and diameter respectively. Eq. 6 is particularly useful when dealing with mixtures of solids, as an equi-partition of (random) kinetic energy means that $\theta$ is the same for each phase.

\subsection{Simulation procedure}

\section{Domain:}

The simulation domain grids were irregular triangular mesh elements following the TriPave face meshing scheme using GAMBIT, a meshing tool built in FLUENT package. The mesh spacing was defined with a fine grid at the nozzle tip and grows up to a maximum grid size of $5 \times 10^{-3} \mathrm{~m}$ at the top of the fluidized bed. The simulation domain is illustrated in Fig. 3.

\section{Procedure:}

In solving the model equations, two different discretisation schemes were set; the second order UPWIND method for the momentum and granular temperature equations, 
and the QUICK method for the volume fraction transport equation. A time step of $10^{-4} \mathrm{~s}$ and 200 iterations per step was used. The relative errors between two successive iterations were specified by a convergence criterion of $10^{-4}$ for each scaled residual component. For each case, the simulation was considered for 20 seconds of real time fluidized bed operation. The first 5 seconds of simulated data was left out to avoid the start up effect. The fluidized bed hydrodynamics throughout the granulation process is represented by the fluidization behaviour of the primary particles $(200 \mu \mathrm{m})$. It is acknowledged that particle-particle collision rate varies with evolving granule size during granulation. However, the choice was made here to work with a constant primary particle size for tour reasons: (i) avoid complicated and time consuming coupling of multi-sized particle mixture (ii) rapid aggregation takes place at the early granulation stage (Tan et al., 2006); within this range the variation in collision rate is relatively insignificant; (iii) FBMG experimental results have shown that aggregation rate constant does not vary with particle size (Tan et al., 2006). In terms of air fluidization velocities, different ranges between $0.83 \mathrm{~m} / \mathrm{s}$ and $1.11 \mathrm{~m} / \mathrm{s}$ were considered in the simulation. $A$ summary of the simulation parameters is given in Table 2 .

\section{Boundary conditions:}

The continuous (gas) and disperse (solid) phases are assumed to obey a no-slip boundary condition at the vessel wall. The bottom and top boundary condition were modeled using a constant velocity boundary condition. For the energy equation, the following boundary condition of Johnson and Jackson (1987) was used:

$k_{s} \frac{\partial \theta}{\partial y}=\frac{\sqrt{3} \pi \rho_{s} g_{o} \varepsilon_{s} \sqrt{\theta}}{6 \varepsilon_{s-\max } \mu_{s}}\left[\varphi\left|u_{s}\right|^{2}-\frac{3 \theta}{2}\left(1-e_{w}^{2}\right)\right]$

where the term in the left represents the energy flux at the wall, the first term in the right represents the energy generation due to particles slip at the wall and the second term represents the energy dissipation due to inelastic particle collisions with the wall.

\section{Spray nozzle:}

The air nozzle was represented with a velocity boundary condition. A finer grid at the nozzle tip, as described earlier, was used to ensure capturing the steep variations of the 
flow hydrodynamics near the spray zone. This choice was also found to be appropriate to avoid convergence problem while keeping the computational time at a reasonable level. The value of the air velocity at the nozzle tip was obtained from a 3D simulation carried out specifically to determine the jetting air velocity at 1.5 bar gauge pressure (average operating pressure in a typical spray granulator). The corresponding air velocity was found to be $20.0 \mathrm{~m} / \mathrm{s}$.

\section{Validation of the CFD model}

The reliability of granule-granule or granule-droplet analysis presented in the next sections relay strongly on the accuracy of the CFD predictions of the granules spatial concentration and granular temperature. Therefore, it was important to validate the CFD hydrodynamic predictions with experimental data. For this purpose, a pressure transducer (DNX, $40 \mathrm{mb}$ gauge, $\pm 0.4 \% \mathrm{FS}$ accuracy), flushed to the side wall of the fluidized bed, was used to record pressure fluctuations at $7 \mathrm{~cm}$ above the bottom plate and at the rate of $100 \mathrm{~Hz}$. Apart from being non-intrusive and simple, this method is believed to be particularly relevant here, as it is indirect measure of the overall bed expansion (granules distribution) and particle dynamics (granular temperature), the two most important parameters of concern here.

Fig. 4 show samples of the comparison between the CFD and experiment, based on:

i. Pressure fluctuation profile and its mean, $\bar{P}$,

ii. Dominant frequency, $f_{1}$, obtained from Fast Fourier Transform (FFT) analysis,

iii. Standard deviation of pressure fluctuations, $\sigma_{p}$.

It is evident that there is good match between the CFD and the experiments in terms of the particles dynamics and fluctuations. This is assumed satisfactory for the current intended application and objectives. 


\section{Theoretical derivations of collision rate models}

\subsection{Granule-granule collision rate}

The rate of collisions per unit volume, $R_{s-s}$, between the granules can be related to their concentration per unit volume, $N_{s}$, as follows:

$R_{s-s}=\beta_{c} N_{s}^{2}$

where $\beta_{c}$ is the aggregation rate constant, or kernel. The time scale for collisions is then given by:

$\tau_{s-s}=\frac{N_{s}}{R_{s-s}}=\frac{1}{\beta_{c} N_{s}}$

Previously, Goldschmidt (2001) has shown that the collision rate constant for granules of diameter $d_{s}$ can be related to the granular temperature, $\theta$, and the radial distribution function, $g_{0}$, by:

$\beta_{c}=4 g_{0} d_{s}^{2} \sqrt{\pi \theta}$

With the solid concentration in hand from the CFD simulation, the number concentration of granules per unit volume can be given by:

$N_{s}=\frac{\varepsilon_{s}}{\frac{\pi}{6} d_{s}^{3}}$

Substituting Eqs. 10 and 11 into Eq 9 yields:

$\tau_{s-s}=\frac{d_{s}}{24 g_{0} \varepsilon_{s}} \sqrt{\frac{\pi}{\theta}}$

Eq. 12 provides the time interval between two successive granule-granule collisions. The reciprocal provides the granule-granule collision rate per second. 


\subsection{Droplet-Granule collision rate}

With the assumption that the droplet flux from the nozzle flow in a symmetric pattern in a conical shape of half-angle $\phi$, with the nozzle at the apex of the cone (see Fig. 5), the following two models for droplet-granules collisions are devloped.

\subsubsection{Ballistic model (high-velocity droplets)}

If the droplets are moving with a velocity $U_{D}$, that is much greater than the granule velocities, then the number flow of droplets, $\dot{N}_{D}$ at a radius, $r$, can be related to the local concentration of droplets, $N_{D}$, by:

$\dot{N}_{D}=4 \phi r^{2} U_{D} N_{D}$

and the rate of droplet-particle collisions per unit volume is given by multiplying the droplet deposition rate $\left(=\frac{\pi}{4}\left(D+d_{s}\right)^{2} U_{D} N_{s}\right)$ by the total droplet concentration, $N_{D}$, such that,

$$
R_{D-s}=\frac{\pi}{4}\left(D+d_{s}\right)^{2} U_{D} N_{s} N_{D}
$$

where $D$ and $d_{s}$ are the diameters of droplet and particle respectively.

From the perspective of the granules, a collision occurs on average with a time interval given by:

$\tau_{D-s}=\frac{N_{s}}{R_{D-s}}$

Now, substituting Eq. 14 in Eq. 15 and replacing $N_{D}$ with that from Eq. 13 gives:

$$
\tau_{D-s}=\frac{1}{\frac{\pi}{4}\left(D+d_{s}\right)^{2} U_{D} N_{D}}=\frac{16 \phi r^{2}}{\pi\left(D+d_{s}\right)^{2} \dot{N}_{D}}
$$

A number balance on droplets gives,

$$
\frac{d \dot{N}_{D}}{d r}=-4 \phi r^{2} R_{D-s}=-\frac{\pi}{4}\left(D+d_{s}\right)^{2} N_{s} \dot{N}_{D}
$$


On the assumption that granule diameter and concentration are not functions of position within the spray zone, Eq. 17 can be integrated to give:

$\dot{N}_{D}(r)=\dot{N}_{D}(0) \exp (-r / Z)$

where

$$
Z=\frac{4}{\pi\left(D+d_{s}\right)^{2} N_{s}}=\frac{2 D^{3}}{3 \varepsilon_{s}\left(D+d_{s}\right)^{2}}
$$

Substituting Eq. 18 into Eq. 16 gives the droplet-granule collision time scale as a function of position in the spray zone as follows:

$$
\tau_{D-s}=\frac{16 \phi r^{2}}{\pi(D+d)^{2} \dot{N}_{D}(0)} \exp (r / Z)
$$

where $N_{s}$ is given by Eq. 11 and the number spray rate of droplets can be obtained from the binder mass spray rate, $\dot{M}_{D}$, as follows:

$$
\dot{N}_{D}(0)=\frac{\dot{M}_{D}}{\frac{\pi}{6} d_{s}^{3} \rho_{L}}
$$

Substituting Eqs. 21 and 19 into Eq. 20 gives the final equation for the droplet-granule collision time scale as follows:

$$
\tau_{D-s}=\frac{8 \phi r^{2} d^{3} \rho_{L}}{3\left(D+d_{s}\right)^{2} \dot{M}_{D}} \exp \left(\frac{3\left(D+d_{s}\right)^{2} \varepsilon_{s} r}{2 D^{3}}\right)
$$

The beauty of Eq. 22 is that it provides simple theoretical estimation of granule-droplet collision rate once the binder density and spray rate $\left(\rho_{L}\right.$, and $\left.\dot{M}_{D}\right)$ and droplet and particle sizes ( $D$ and $d_{s}$ ) are in hand. The particle concentration within the spray zone, $\varepsilon_{s}$, generally varies within the range of $0.02-0.08$, however, this can be accurately obtained from CFD simulation as shown in section 5.3 . 


\subsubsection{Kinetic theory model}

If the droplet travels at a velocity similar to the granule velocity, then it can be assumed that the droplet-granule collisions are induced by random fluctuations in velocity described by a mixture granular temperature $\theta_{s}$. In this case the rate of collisions will be given by:

$$
R_{D-s}=\sqrt{\frac{\theta_{s}}{\rho_{s}}} g_{o} N_{D} N_{s}\left(D+d_{s}\right)^{2}\left(D^{-1.5}+d_{s}^{-1.5}\right)
$$

Now, replacing the mixture granular temperature in the above equation with that of Eq. 6 gives:

$$
\frac{d \dot{N}_{D}}{d r}=\sqrt{\frac{6 \theta}{\pi}} \frac{g_{o} \dot{N}_{D} \varepsilon_{s}\left(D+d_{s}\right)^{2}\left(D^{-1.5}+d_{s}^{-1.5}\right)}{U_{D} D^{1.5}}
$$

which then following the same integration employed to Eq. 17 gives the number flow of droplets same as in Eq. 18, but with a different formulation for $Z$ given by:

$$
Z=\sqrt{\frac{\pi}{6 \theta}} \frac{U_{D}}{g_{o} \varepsilon_{s}} \frac{D^{1.5}}{\left(D+d_{s}\right)^{2}\left(D^{-1.5}+d_{s}^{-1.5}\right)}
$$

this allows the droplet-granule collision time to be determined from Eqs. 21, 23 and 24 as follows:

$$
\tau_{D-s}=\frac{N_{s}}{R_{D-s}}=\sqrt{\frac{8 \pi}{3 \theta}} \frac{U_{D} \rho_{L} \phi d_{s}^{3}}{g_{o} \dot{M}_{D} D^{1.5}\left(D+d_{s}\right)^{2}\left(D^{-1.5}+d_{s}^{-1.5}\right)} r^{2} \exp (r / Z)
$$

Similar to Eq. 22, this equation provide a simple approach to estimating the granuledroplet collision rate once the operating conditions are available. The granular temperature, $\theta_{s}$, and radial distribution function, $g_{o}$ (function of solid concentration) within the spray zone can both be obtained from CFD simulation, as shown in section 5.3 . 


\subsection{CFD predictions of flow dynamics}

Fig. 6 shows contour diagrams of the spatial variation of the granular temperature, solid velocity and solid concentration in the spray fluidized bed. It is interesting to note how the spray nozzle affects the general hydrodynamics as indicated by the distinct behavior downstream the spray nozzle. Such a detailed hydrodynamic quantification is important for the analysis of granule-granule and granule-droplet interactions in such systems

Fig. 6a shows the spatial variation of the granular temperature. A distinct zone characterised by higher granular temperature can be observed around the spray nozzle, implying that the granules are experiencing higher collision rates in this region. This is mainly due to high granule fluctuation velocity resulting from the atomizing air flow effects. The spatial variation of granule velocity magnitude is shown in Fig 6b. The effect of the spray nozzle on the granule motion is also well pronounced here. Granules within the spray zone area are rapidly pushed towards the bottom under the influence of air spray nozzle. Fig. $6 \mathrm{c}$ shows that the solid are concentrated at the walls, while the region around the spray nozzle is surrounded by a dilute phase, again mainly due to the atomizing air pressure pushing the solids away from the air jetting effects.

\subsection{Spatial and temporal averaging}

Since binder is injected from the nozzle, most of the aggregation process would occur in the region near to the nozzle. Therefore, granule-granule collision time scales near to the nozzle need to be carefully averaged in order to give accurate representation of the flow dynamic in this region. The averaging procedure was specifically carried out to calculate $\varepsilon_{s} \sqrt{\theta}$, an important quantity required to estimate the granule-granule collision rate according to Eq. 12. A total of 10 seconds CFD data of $\varepsilon_{s} \sqrt{\theta}$ for each computational cell were time-averaged at time step of 1 millisecond. The time averaged $\varepsilon_{s} \sqrt{\theta}$ as function of the distance from the spray nozzle tip is shown in Fig. 7. Applying this into Eq. 12 gives the time averaged granule-granule collision time scale. 
In obtaining the volume averaged granule-granule collisions at the spray zone according to Eq. 12, a spatial averaging procedure was adopted in order to ensure good representation of the averaged spray zone behaviour. This was carried out by averaging the data collected across the equally separated segments as shown in Fig. 5a. This is descried mathematically as follows:

$\left(\varepsilon_{\mathrm{s}} \sqrt{\theta}\right)_{\text {mean }}=\frac{\sum_{i=1}^{i=n}\left(\varepsilon_{\mathrm{s}} \sqrt{\theta}\right)_{i} V_{i}}{\sum_{i=1}^{i=n} V(i)}$

$V_{i}=\frac{1}{3} \pi \tan ^{2}(\phi)\left(r_{i}^{3}-r_{i-1}^{3}\right)$

where $\left(\varepsilon_{s} \sqrt{\theta}\right)_{i}$ is time averaged quantity for the $\mathrm{i}^{\text {th }}$ segment. Eq. 27 gives time-volume averaged granular temperature over the spray zone and Eq. 28 gives the volume of the $\mathrm{i}^{\text {th }}$ segment.

\subsection{Implementation of the collision models}

\subsubsection{Granule-granule collisions}

The time averaged granule-granule collision time scale, $\tau_{s-s}$, within the spray zone as function of the distance from the nozzle tips shown in Fig. 8. Clearly, the collision rate is slower away from nozzle tip as the effect of atomizing air diminishes. $\tau_{s-s}$ approximately varies between $10^{-3}$ and $10^{-2} \mathrm{~s}$ within the first $5 \mathrm{~cm}$ segment, beyond that the data is quite scattered but remain within the limit of $2 \times 10^{-2} \mathrm{~s}$.

Fig. 9 shows the time-volume averaged granule-granule collision time scales in the spray zone as function of fluidization velocity. The collision was averaged over a volume limited to a distance of $Z=5 \mathrm{~cm}$ from the apex of the spray zone and a half angle $\phi=$ $22.5^{\circ}$. We will justify the use of $5 \mathrm{~cm}$ to represent spray zone in section 6.3.3. Fig. 9 demonstrates a strong dependence of granule-granule collision rate on the fluidization velocity. The collision time scale halves when increasing the velocity from $0.83 \mathrm{~m} / \mathrm{s}$ to $1.1 \mathrm{~m} / \mathrm{s}$. This trend is expected since increasing the gas velocity give rise to high 
granular temperature, which in turn results in decreasing the collision time scale according to Eq. 10.

\subsubsection{Droplet-granule collisions}

The hydrodynamic parameters given in Table 3 are assumed to give a reasonable representation of the average operating conditions considered in this study. The spray rate corresponds to 1.5 bar atomizing air pressure. Applying these parameters into the kinetic theory and ballistic models, one can obtain the droplet-granule collision time scale as function of the distance from the tip of the spray nozzle as shown in Fig. 10. It is indicated that rapid collision takes place at the nozzle tip $\left(\tau_{D-s}<1.0^{-4} \mathrm{~s}\right)$, which then exponentially decays when moving away from the vicinity of the spray zone.

In an effort to shed more light on the interaction between binder droplets and granules we compare the droplet-granule collision time scales shown in Figs. 10 with the timevolume averaged granule-granule collision time scale in Fig. 9. In the region where droplet-granule collision time is shorter than granule-granule collision time, it is believed that the droplet number has considerably decayed. Hence, using this as a criterion, one can identify the boundary (i.e. distance from the spray nozzle tip), where binder deposition or liquid coating process takes.

Taking the slowest fluidization velocity considered in this study $(0.83 \mathrm{~m} / \mathrm{s})$, Fig. 9 shows that the granule-granule collision time scale is $\sim 0.016 \mathrm{~s}$. Fig. 10 shows that the dropletgranule collision time scale is shorter than this for an approximate distance of $r<1.2$ $\mathrm{cm}$ (for both ballistic and kinetic theory models). Thus, it is safe to conclude that droplet deposition in this case mainly takes place rapidly within a very short distance from the spray nozzle tip.

\subsubsection{Identification of spray zone boundary}

It is acknowledged that a clear cut boundary of the spray zone is difficult to identify, however, if the droplet decay away from the spray zone can be quantified, then an estimate of the spray zone length can be realized. The number droplet flow rate given 
earlier in Eq. 18, shows that the initial droplet concentration decays rapidly with an exponent $-r / Z$. This is shown graphically in Fig. 11. It is clear that, at $r / Z \sim 5$, there is virtually no droplet left, which then implies a maximum spray zone length of $r=5 Z$, where $Z$ is given by Eq. 19 or Eq 25 depending on the droplet-granule model used.

Substituting the parameters in Table 3 into Eq. 19 from the ballistic model and Eq. 25 from the Kinetic theory, gives $Z=0.23 \mathrm{~cm}$ and $Z=1.7 \mathrm{~cm}$ respectively. According to the analysis above, the spray zone length is five times these values. Taking the average $Z$ value and multiply by 5 gives an estimated average spray zone length of $\sim 5 \mathrm{~cm}$. This justifies the length scale used in the CFD volume averaging as discussed earlier.

\section{Conclusion}

In this paper, the rates of granule-granule collision and granule-droplet collision in a FBMG have been analyzed theoretically with the aid of CFD predictions of granules dynamics. This is the first part of a comprehensive time scale analysis of various events occurring in the spray fluidized bed as summarized in Figs. 1 and 2.

The CFD predictions revealed interesting hydrodynamic features of a spray fluidized bed indicated by clear inhomogeneity and distinct granule behaviour around the spray nozzle zone. Due to this inhomogeneity, a spray active region has to be identified. For the range of operating conditions considered here, the result reveals that granulegranule collision within the spray zone occurs at a time scale in the range of $10^{-3} \mathrm{~s}$ and $10^{-2} \mathrm{~s}$, while the droplet-granule collision within the vicinity of the spray nozzle tip occurs at a much faster rate well below $10^{-4} \mathrm{~s}$, however, this decays rapidly towards the end of the spray zone limit.

In the second and third part of this study focus will be made on time scale analysis of droplet spreading and solidification. Understanding and developing methods for controlling the rate of these events is a key feature for improving the efficiency of FBMG operation. 


\section{ACKNOWLEDGMENT}

Kel W. Chua would like to thank the Engineering and Physical Science Research Council (EPSRC) and the Department of Chemical and Process Engineering at the University of Sheffield for a PhD scholarship. 


\section{Notation}

$C \quad$ fluctuating component of particle velocity $\left(\mathrm{m} \mathrm{s}^{-1}\right)$

$C_{d} \quad$ drag coefficient (-)

$D \quad$ droplet diameter $(\mathrm{m})$

$d_{s} \quad$ solid/granule diameter $(\mathrm{m})$

$e_{s s}, e_{w} \quad$ granule-granule and granule-wall restitution coefficient, $=0.8$ and 0.9 respectively (-)

$g \quad$ gravity acceleration constant $\left(\mathrm{m} \mathrm{s}^{-2}\right)$

$g_{0} \quad$ radial distribution function (-)

$I_{2 D} \quad$ second invariant of diviatoric stress tensor $\left(\mathrm{s}^{-2}\right)$

$k_{s} \quad$ effective thermal conductivity of particles $\left(\mathrm{kg} \mathrm{m}^{-1} \mathrm{~s}^{-1}\right)$

$\dot{M}_{D} \quad$ injection rate of droplet $\left(\mathrm{g} \mathrm{s}^{-1}\right)$

$N \quad$ number concentration per unit volume $\left(\mathrm{m}^{-3}\right)$

$\dot{N} \quad$ number flow $\left(\mathrm{s}^{-1}\right)$

$p, p^{*} \quad$ gas and solid pressure respectively $\left(\mathrm{kg} \mathrm{m}^{-1} \mathrm{~s}^{-2}\right)$

$r \quad$ spray radial coordinate $(\mathrm{m})$

$\mathrm{Re}_{s} \quad$ Reynolds number (-)

$R_{D-s} \quad$ rate of droplet-granule collisions per unit volume $\left(\mathrm{m}^{-3} \mathrm{~s}^{-1}\right)$

$R_{s-s} \quad$ rate of granule-granule collisions per unit volume $\left(\mathrm{m}^{-3} \mathrm{~s}^{-1}\right)$

$U_{D} \quad$ droplet velocity $\left(\mathrm{m} \mathrm{s}^{-1}\right)$

$u \quad$ granule velocity $\left(\mathrm{m} \mathrm{s}^{-1}\right)$

$u_{r, s} \quad$ granule terminal velocity $\left(\mathrm{m} \mathrm{s}^{-1}\right)$

$V \quad$ volume of spray segment $\left(\mathrm{m}^{3}\right)$

$\mathrm{Z} \quad$ spray characteristic length $(\mathrm{m})$

Greek symbols

$\eta \quad$ parameter function of particle-particle restitution coefficient, $=\left(1+e_{s s}\right) / 2(-)$

$\tau_{s-s} \quad$ granule-granule collision time scale (s)

$\tau_{D-s} \quad$ droplet-granule collision time scale (s)

${ }_{\tau}^{=} \quad$ stress tensor $\left(\mathrm{kg} \mathrm{m}^{-1} \mathrm{~s}^{-2}\right)$

$\beta_{c} \quad$ collision kernel $\left(\mathrm{m}^{3} \mathrm{~s}^{-1}\right)$

$\beta \quad$ gas-solid interphase coefficient (-)

$\theta \quad$ granular temperature $\left(\mathrm{m}^{2} \mathrm{~s}^{-1}\right)$

$\theta_{s} \quad$ mixture granular temperature $\left(\mathrm{kg} \mathrm{m}^{2} \mathrm{~s}^{-1}\right)$

$\varepsilon_{s} \quad$ volume fraction of solid (-)

$\varepsilon_{s}^{*} \quad$ critical volume fraction of solid,$=0.59(-)$

$\varepsilon_{s-\max } \quad$ Maximum allowable volume fraction of solid, $=0.6(-)$

$\rho \quad$ density $\left(\mathrm{kg} \mathrm{m}^{-3}\right)$ 


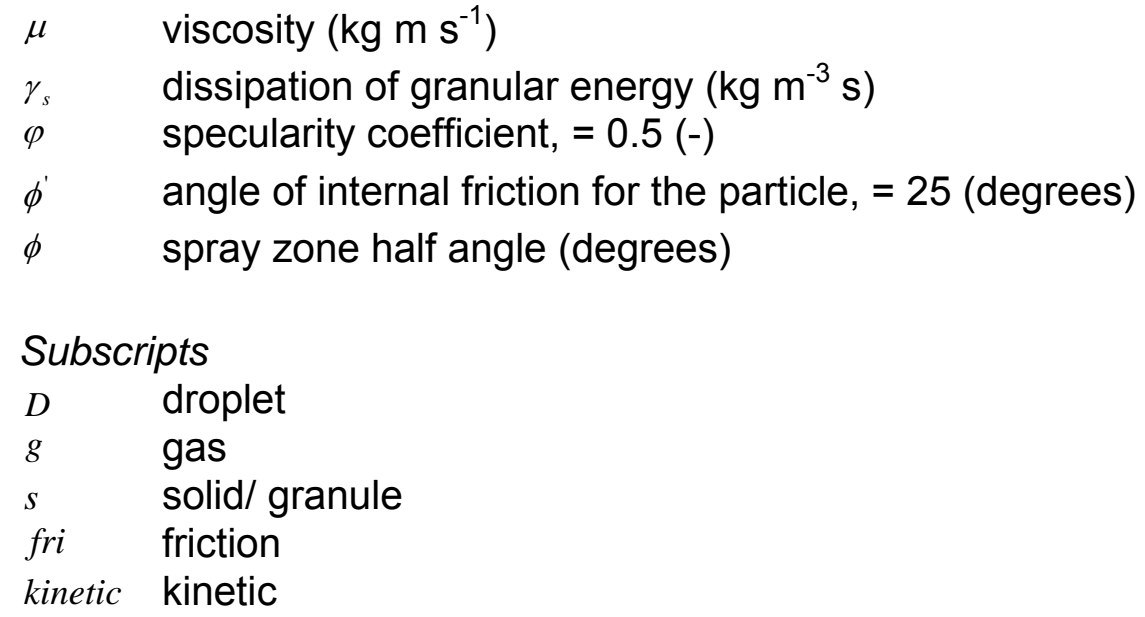




\section{References}

Ding, J., Gidaspow, D. A bubbling fluidization model using kinetic theory of granular flow. AIChE J. 1990, 36, 523-538.

Fluent 6.3, 1996. Fluent 6.3 Users Guide. Lebanon, NH, 1996, Ansys Inc.

Goldschmidt, M., 2001. Hydrodynamic Modelling of Fluidized Bed Spray Granulation. Fundamental Aspects of Chemical Reaction Engineering research group. Enschede, University of Twente. PhD Thesis.

Heinrich, S., Peglow, M, Ihlow, M., Henneberg, M., Morl, L., 2002. Analysis of the startup process in continuous fuidized bed spray granulation by population balance modeling. Chemical Engineering Science, 57, 4369 - 4390

Johnson, P., Jackson, R., 1987. Frictional-collisional constitutive relations for granular materials, with application to plane shearing. Journal of Fluid Mechanics, 176, 67-93

Lun, C. K. K., Savage, S. B. S., Jeffrey, D. J., Chepurniy, N., 1984. Kinetic Theories for Granular Flow: Inelastic Particles in Couette Flow and Slightly Inelastic Particles in a General Flow Field. J. Fluid Mech., 140, 223-256.

Schaeffer, D. G.. 1987. Instability in the Evolution Equations Describing Incompressible Granular Flow., J. Diff. Eq., 66, 19-50.

Schaafsma,S. H., Vonk, P, Kossen, N. W. F., Hoffmann, A. C., 2006. A model for the spray zone in early-stage fluidized bed granulation, AICHE, 52, 2736-2741

Sinclair, J. L., Jackson, R., 1989. Gas-particle flow in a vertical pipe with particle-particle interactions. AICHE, 35, 1473-1486.

Syamlal, M., Rogers, W., O'Brien T. J., MFIX Documentation: Volume 1, Theory Guide, National Technical Information Service, Springfield, VA, 1993, DOE/METC-9411004, NTIS/DE9400087.

Syamlal M., O'Brien, T. J., 1989. Computer Simulation of Bubbles in a Fluidized Bed, AIChE Symp., Series 85, 22-31.

Tan, H.S., Goldschmidt, M. J. V., Boerefijn, R., Hounslow, M. J., Salman, A. D, Kuipers, J. A. M., 2004. Building population balance model for fluidized bed melt granulation: lessons from kinetic theory of granular flow. Powder Technology, 142, 103-109.

Tan, H. S., Salman, A. D., Hounslow M. J., 2006. Kinetics of fluidized bed melt granulation I: The effect of process variables. Chemical Engineering Science, 61, 15851601. 
Thielmann, F., Naderi, M., Ansari, M., Stepanek, F., 2008. The effect of primary particle surface energy on agglomeration rate in fluidized bed wet granulation. Powder Technology, 181, 160-168. 


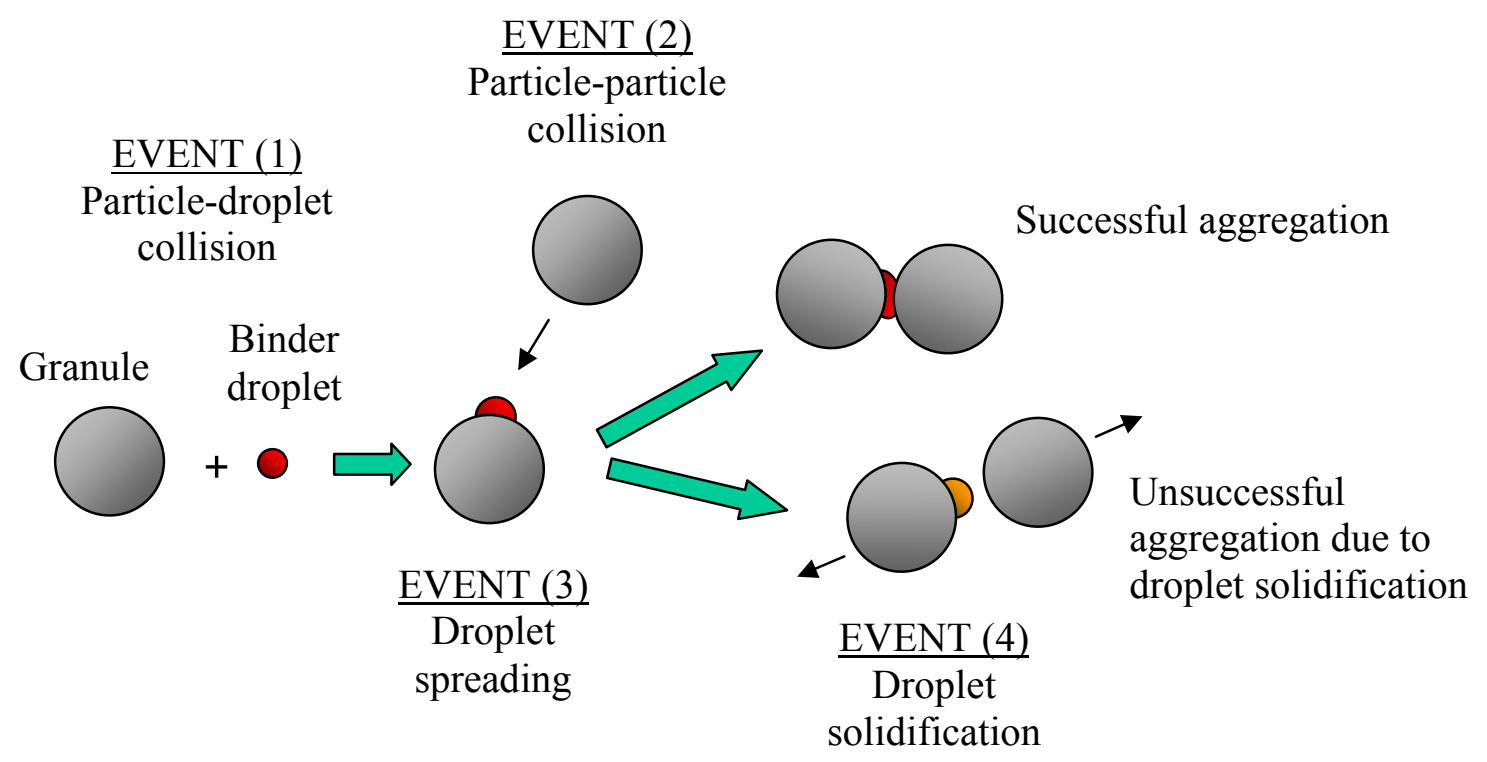

Fig. 1. Schematic of the four microscopic events occurring during FBMG process 


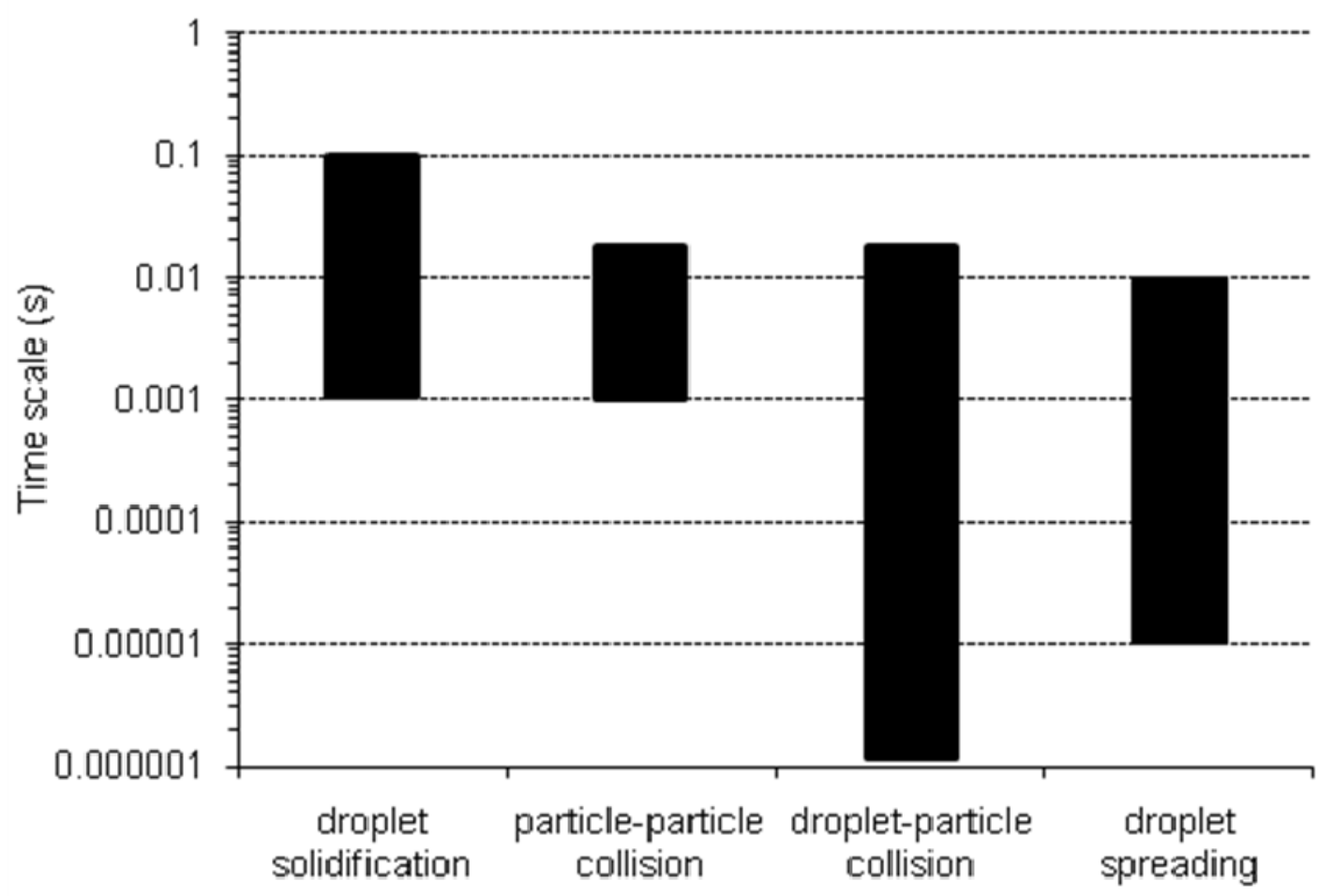

Fig. 2. Comparison between the time scales of different microscopic events occurring during fluidized bed melt granulation (FBMG) with PEG1500 as a binder. 


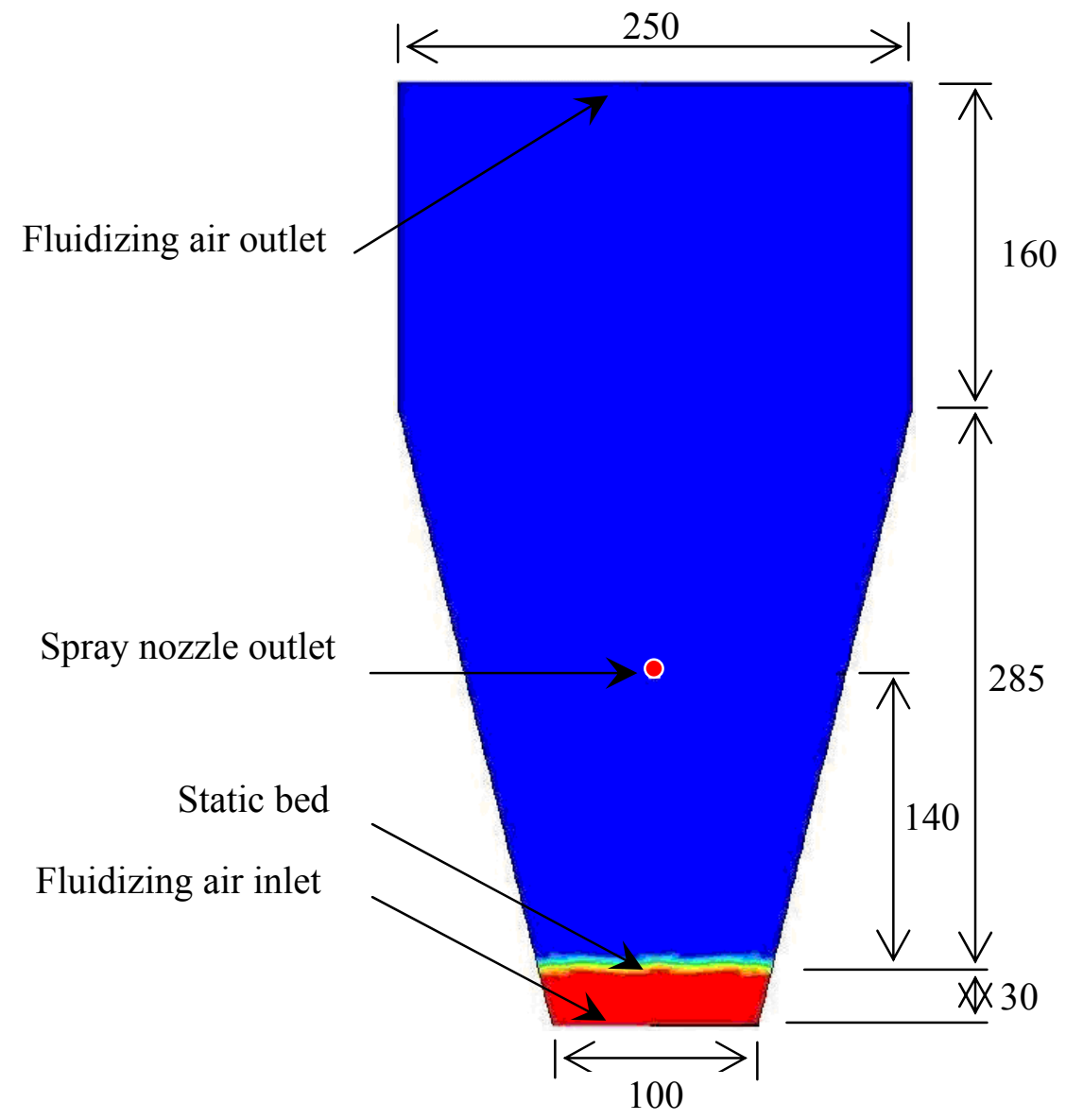

Fig. 3. Simulation domain of the spray fluidized bed. All dimensions are in $\mathrm{mm}$. 
(a)

EXP

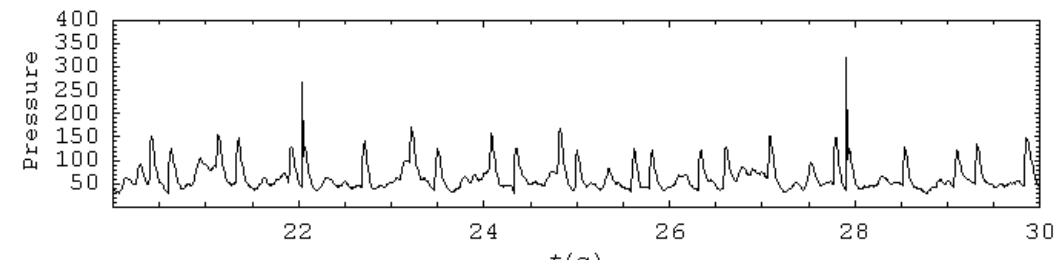

$\overline{\mathrm{P}}=65.02 \mathrm{~Pa}$

$\sigma_{\mathrm{P}}=35.98 \mathrm{~Pa}$

(b)

CFD

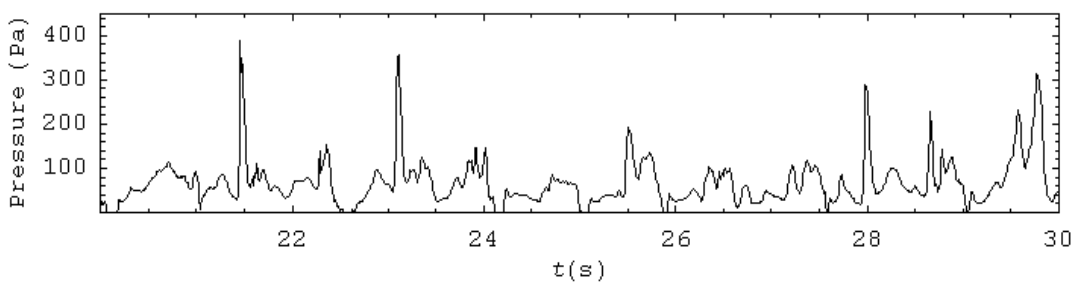

$\overline{\mathrm{P}}=61.73 \mathrm{~Pa}$

$\sigma_{\mathrm{P}}=41.51 \mathrm{~Pa}$

(c)

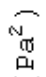

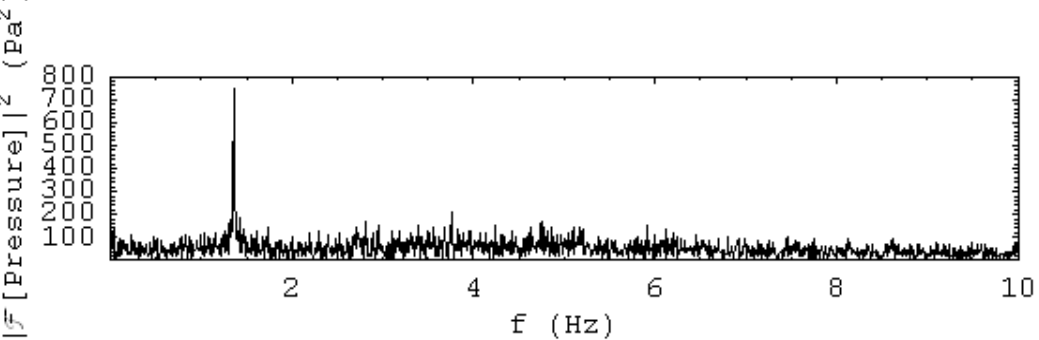

$\mathrm{f}_{1}=1.359 \mathrm{~Hz}$

EXP

th

f ( $\mathrm{Hz})$

$\mathrm{f}_{1}=1.246 \mathrm{~Hz}$

(d)

CFD

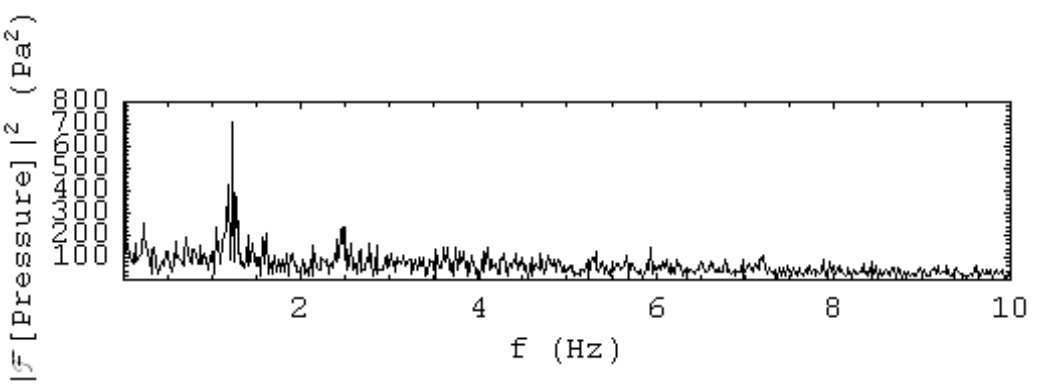

Fig. 5. (a) Pressure profiles from experiment (b) Pressure profiles from CFD (c) Fast Fourier Transform of pressure profile from experiment (d) Fast Fourier Transform of pressure profile from CFD. Atomizing air pressure of 1.0 bar, particle diameter of $200 \mu \mathrm{m}$ and air fluidization velocity of $0.97 \mathrm{~m} / \mathrm{s}$. 


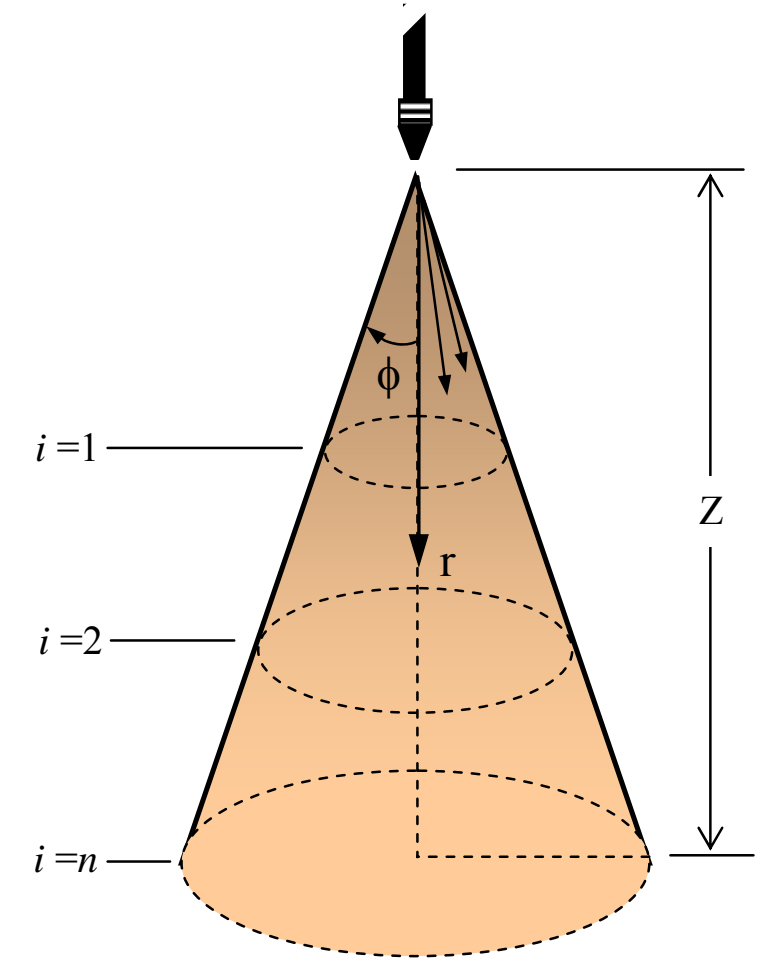

(a)

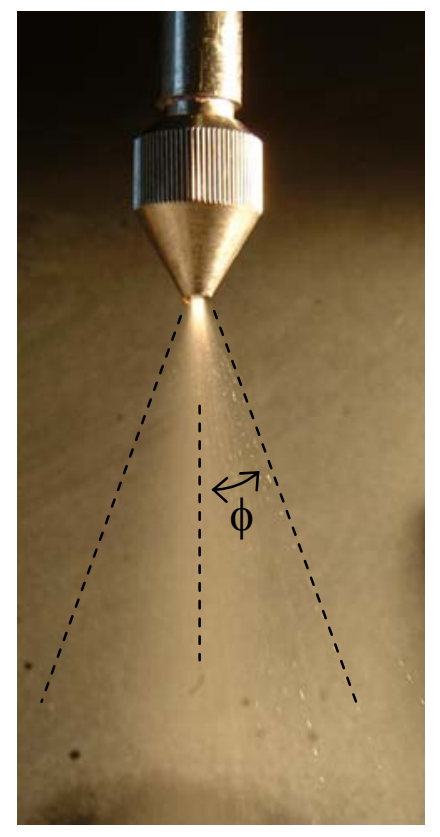

(b)

Fig. 5. (a) Schematic representation of the active spray zone domains and the data averaging segments used in the hydrodynamic averaging method (b) Snapshot image showing a water spray at 1.5 bar atomizing air pressure. Spray angle estimated at $\phi=$ $22.5^{\circ}$. 

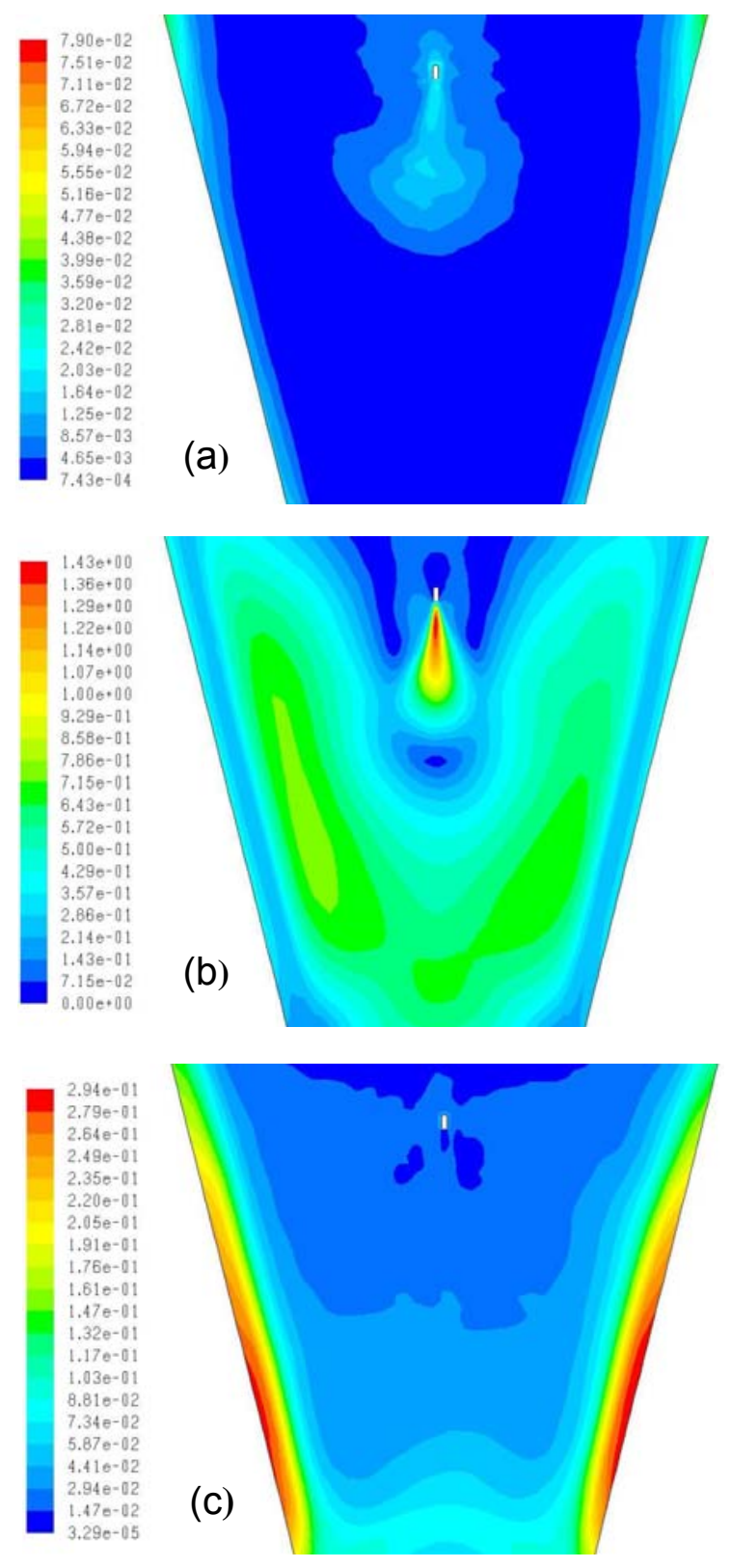

Fig. 6. CFD predictions of spatial variation of the flow dynamics in a spray fluidized bed (a) granular temperature $[\mathrm{m} / \mathrm{s}]^{2}$ (b) solid velocity magnitude $[\mathrm{m} / \mathrm{s}]$ (c) solid concentration. Simulation at fluidizing air velocity of $0.97 \mathrm{~m} / \mathrm{s}$, granule size of $200 \mu \mathrm{m}$, atomizing air pressure of 1.5 bars. 


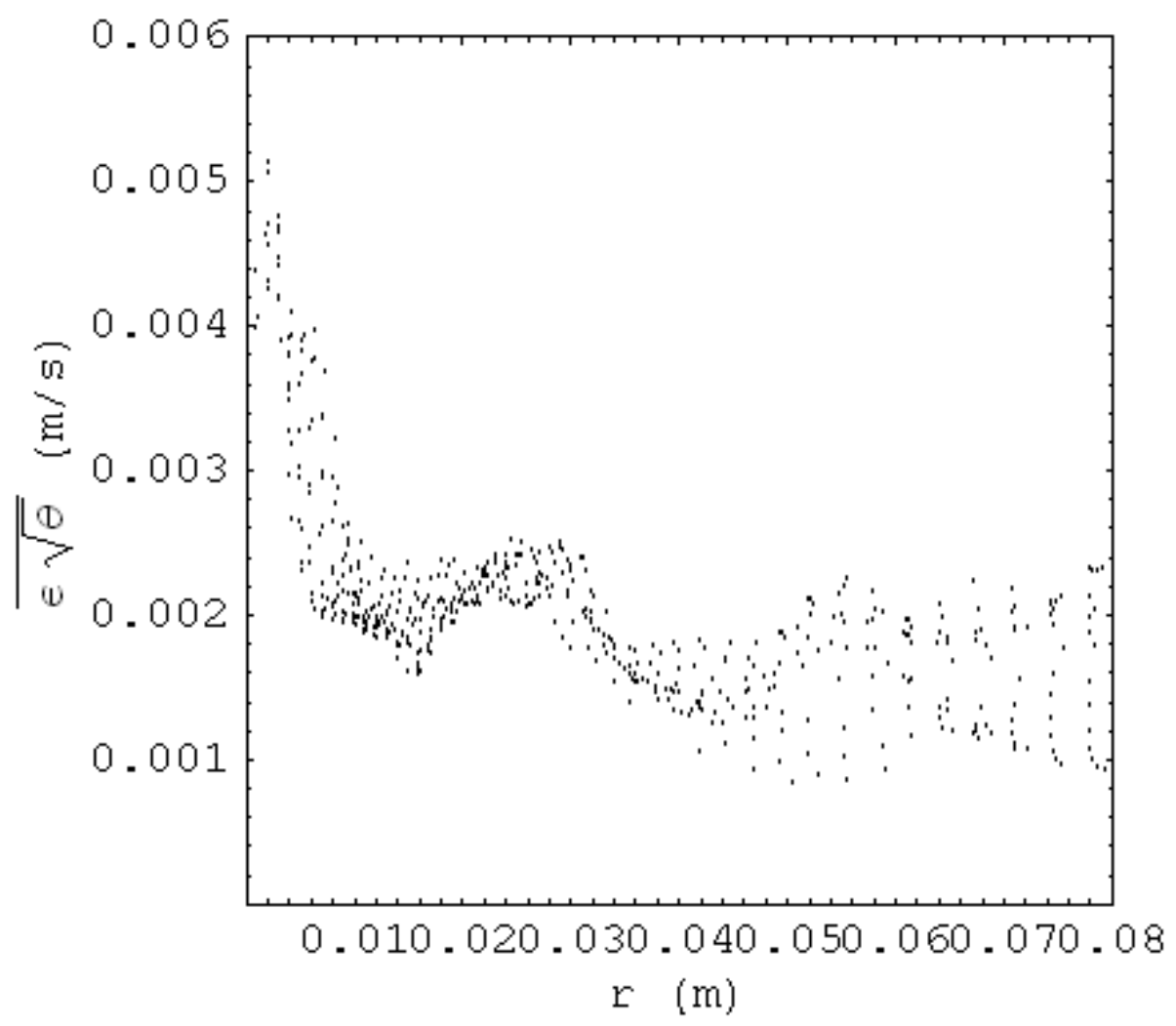

Fig. 7. CFD data for the time averaged granular temperature, $\varepsilon_{s} \sqrt{\theta}$, as function of radial position from the nozzle tip at $0.97 \mathrm{~m} / \mathrm{s}$ fluidizing air velocity, granule size of $200 \mu \mathrm{m}$ and atomizing air pressure of 1.5 bars. 


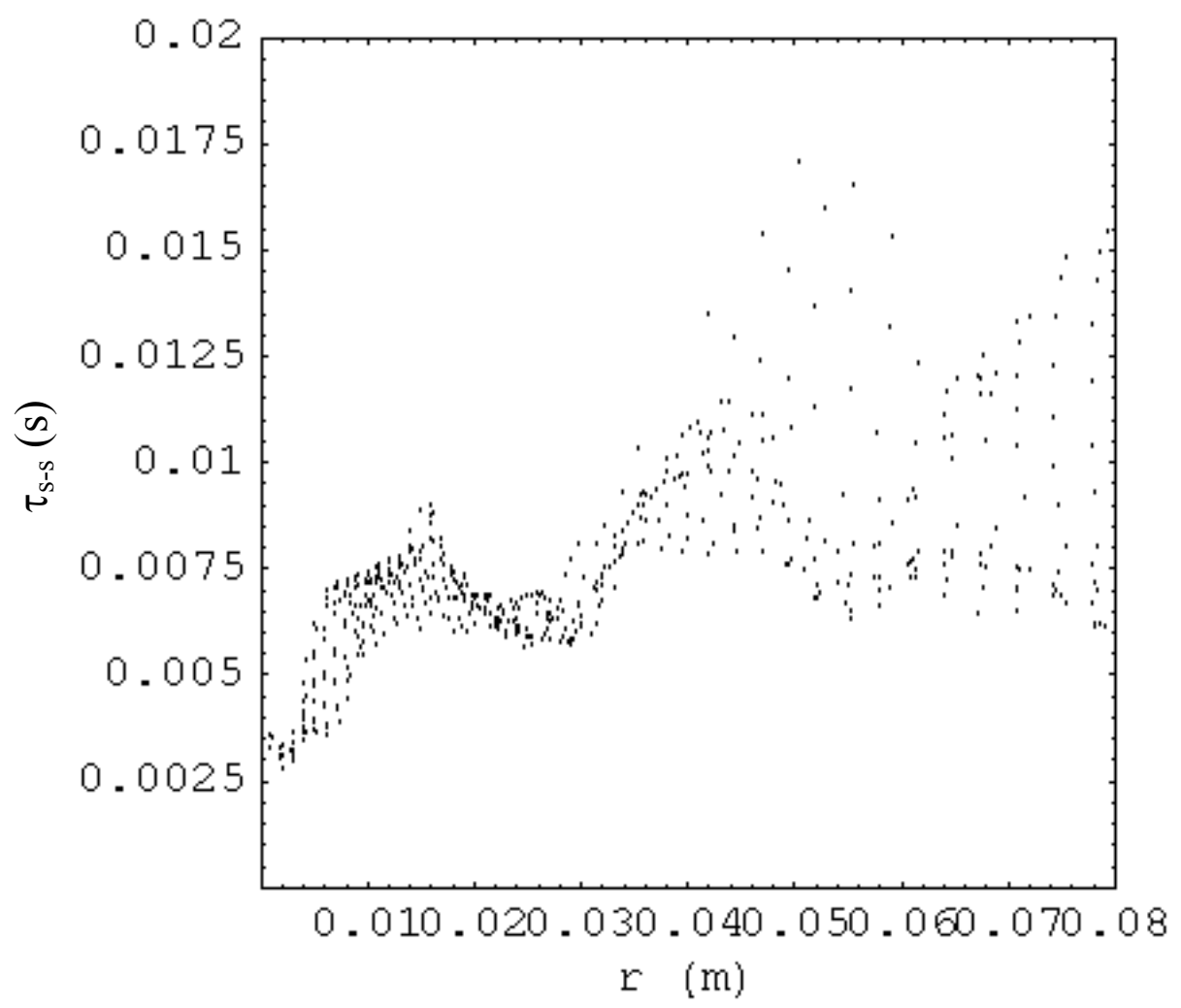

Fig. 8. Variation of the granular-granular collision time scale as function of the distance from the spray nozzle tip at $0.97 \mathrm{~m} / \mathrm{s}$ fluidizing air velocity, granule size of $200 \mu \mathrm{m}$ and atomizing air pressure of 1.5 bars. 


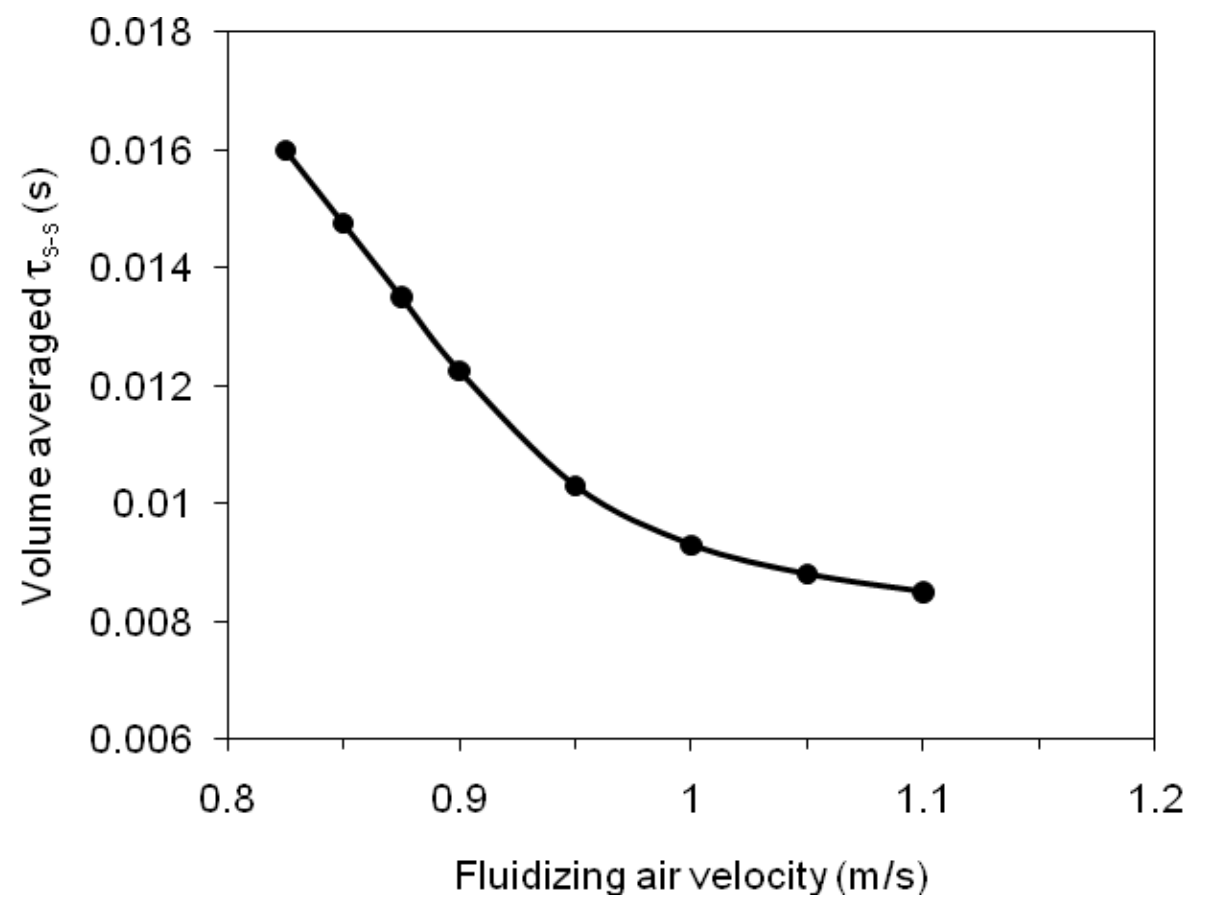

Fig. 9. Time-volume averaged granule-granule collision time scale as function of the gas fluidization velocity for a granule size of $200 \mu \mathrm{m}$. The data was collected over a spray zone length of $5 \mathrm{~cm}$ and $22.5^{\circ}$ spray angle. 


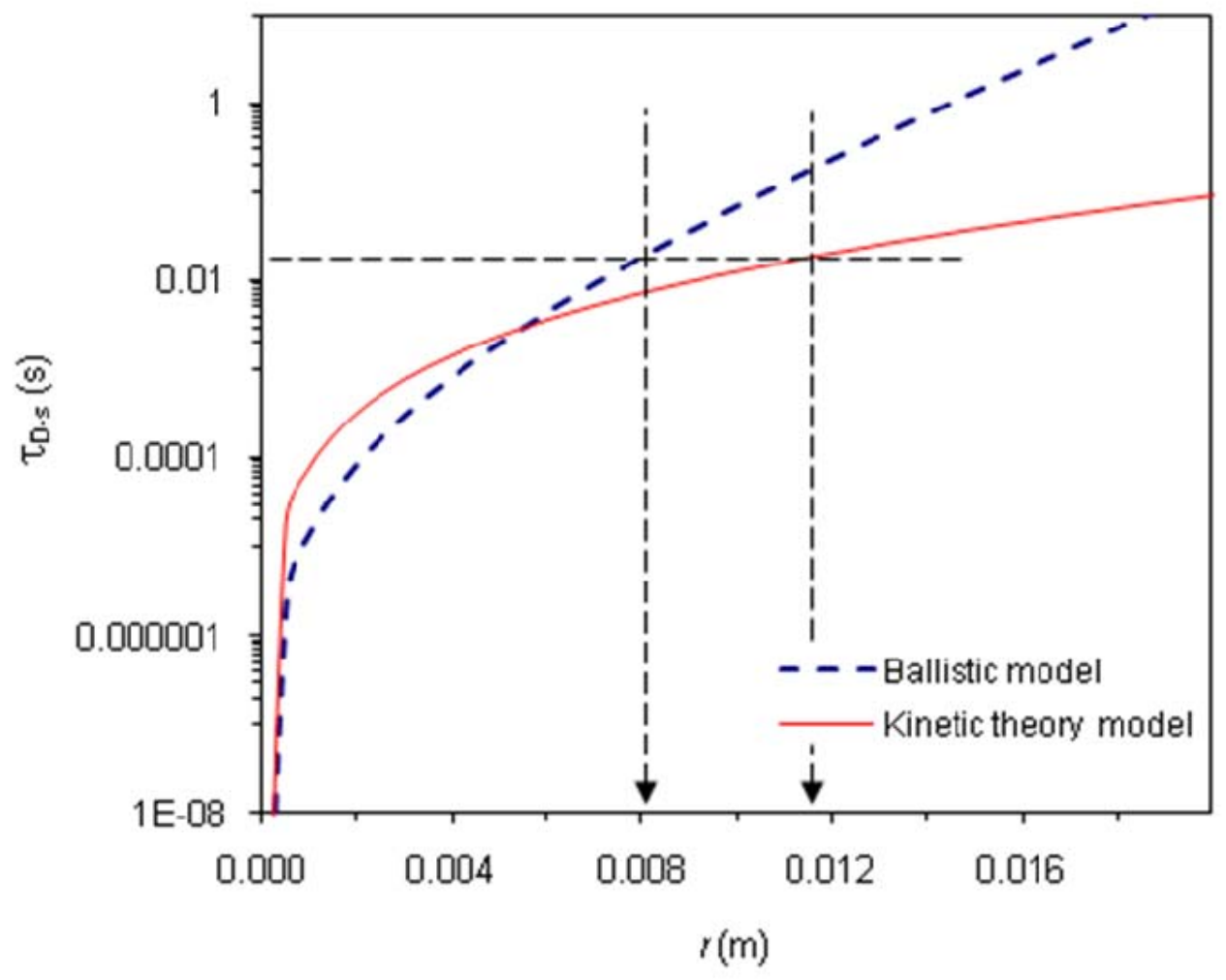

Fig. 10. Droplet-granule collision timescale as a function of the distance from spray nozzle tip calculated according to Eqs. 22 and 26 of the Kinetic theory and Ballistic models respectively. Parameters used are given in Table 3. 


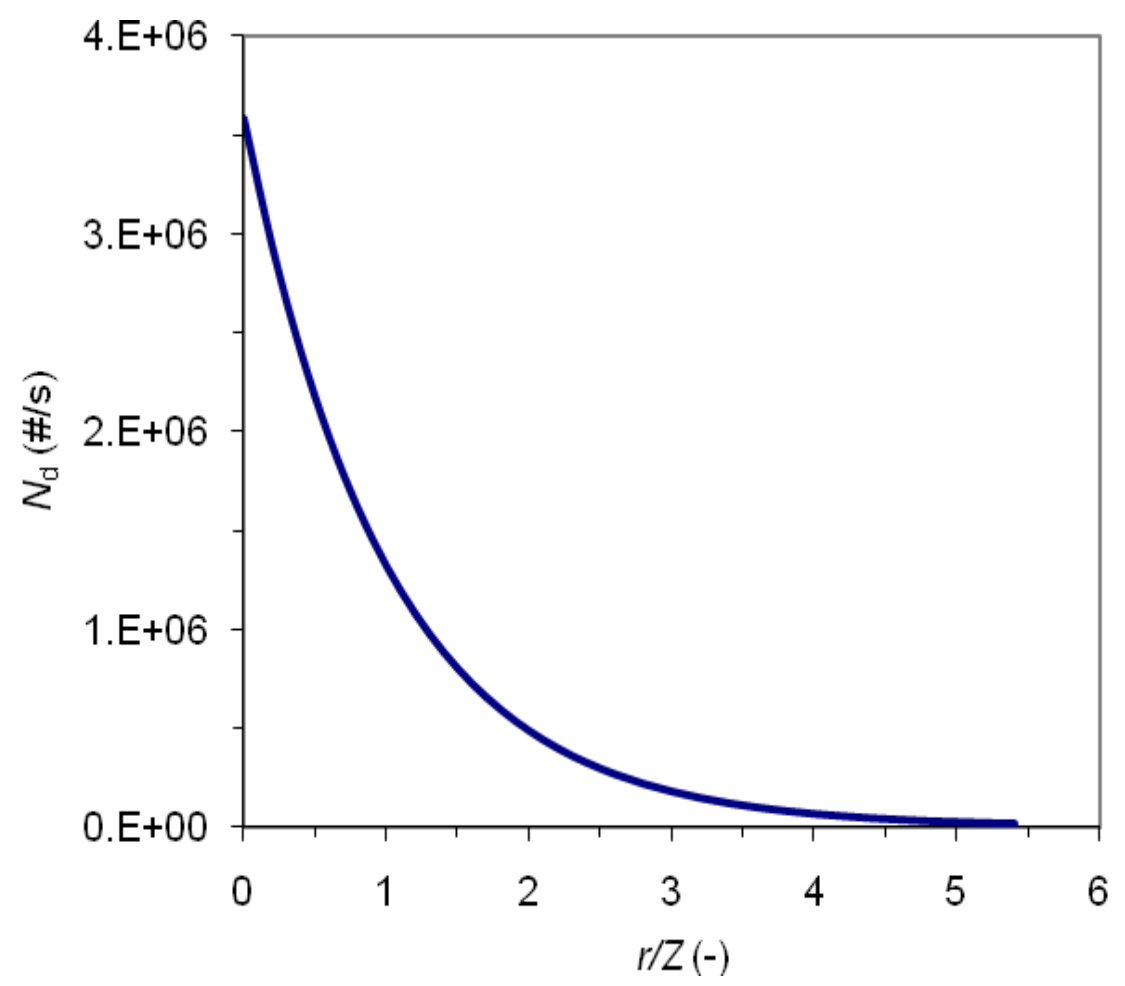

Fig. 11. Droplet number flow rate, calculated according to Eq. 14, as function of the exponent $r / Z$. Operating parameters as given in Table 3 . 
Table 1. Constitutive equations used in the fluidized bed simulation

Drag correlation (Syamlal and O'Brien, 1989)

$$
\begin{aligned}
& \beta=\frac{3 \varepsilon_{s} \varepsilon_{g} \rho_{g}}{4 u_{r, s}^{2} d_{s}} C_{D}\left(\frac{\operatorname{Re}_{s}}{u_{r, s}}\right)\left|\vec{u}_{s}-\vec{u}_{g}\right| \\
& C_{d}=\left(0.63+\frac{4.8}{\sqrt{\operatorname{Re}_{s} / u_{r, s}}}\right)^{2}
\end{aligned}
$$

where

$$
\begin{aligned}
& \operatorname{Re}_{s}=\frac{\rho_{g} d_{s}\left|\vec{u}_{s}-\vec{u}_{g}\right|}{\mu_{g}} \\
& u_{r, s}=0.5\left(\varepsilon_{g}^{4.14}-0.06 \operatorname{Re}_{s}+\sqrt{\left(0.06 \operatorname{Re}_{s}\right)^{2}+0.12 \operatorname{Re}_{s}\left(1.6 \varepsilon_{g}^{1.28}-\varepsilon_{g}^{4.14}\right)+\varepsilon_{g}^{8.18}}\right)
\end{aligned}
$$

Gas stress tensor

$$
\bar{\tau}_{g}=\varepsilon_{g} \mu_{g-e f f}\left(\nabla u_{g}+\nabla u_{g}^{T}\right)
$$

Gas effective viscousity (Sinclair and Jacksons, 1989)

$$
\mu_{g, \text { eff }}=\mu_{g}\left(1+2.5 \varepsilon_{s}+7.6 \varepsilon_{s}^{2}\right)\left(1-\frac{\varepsilon_{s}}{\varepsilon_{s, \max }}\right)
$$

\section{Granular stress tensor}

$$
\begin{aligned}
& \tau_{s}=\varepsilon_{s} \mu_{s}\left(\nabla \cdot u_{s}+\nabla u_{s}^{T}\right)+\varepsilon_{s}\left(\lambda_{s}-\frac{2}{3} \mu_{s}\right) \nabla \cdot u_{s} \bar{I} \\
& \mu_{s}=\mu_{s, k i n}+\mu_{s, \text { coll }}+\mu_{s, f r}
\end{aligned}
$$

kinetic and collisional viscosity (Syamlal et al., 1993)

$$
\begin{aligned}
& \mu_{s, k i n}=\frac{\varepsilon_{s} d_{s} \rho_{s} \sqrt{\theta \pi}}{6\left(3-e_{s s}\right)}\left[1+\frac{2}{5}\left(1+e_{s s}\right)\left(3 e_{s s}-1\right) \varepsilon_{s} g_{0, s s}\right] \\
& \mu_{s, \text { coll }}=\frac{4}{5}\left(1-\varepsilon_{s}\right) \rho_{s} d_{s} g_{o}\left(1+e_{s s}\right) \sqrt{\frac{\theta}{\pi}}
\end{aligned}
$$

Frictional viscosity (Schaeffer et al., 1987)

$$
\mu_{s, f r}=\frac{P_{c} \sin \phi^{\prime}}{2 \sqrt{I_{2 D}}}
$$

where

$$
P_{c}=10^{25}\left(\varepsilon_{s}-\varepsilon_{s}^{*}\right)^{10} \quad \text { if } \varepsilon_{s}>\varepsilon_{s}^{*} \text {, else } P_{c}=0
$$

Bulk viscosity (Lun et al., 1984)

$$
\lambda_{s}=\frac{4}{3} \varepsilon_{s} \rho_{s} d_{s} g_{0, s s}\left(1+e_{s s}\right)\left(\frac{\theta}{\pi}\right)^{1 / 2}
$$


Table 1. Continue

Normal granular pressure (Lun et al., (1984)

$p_{s}=\rho_{s} \varepsilon_{s} \theta+4 \rho_{s} \eta g_{o} \varepsilon_{s}^{2} \theta$

Solid thermal conductivity (Lun et al., (1984)

$k_{s}=\frac{25 \sqrt{\pi \theta} \rho_{s} d_{s}}{128}\left\{\left(\frac{8}{\eta g_{o}}+\frac{96 \varepsilon_{s}}{5}\right)\left(\frac{1+12 / 5 \eta^{2}(4 \eta-3) \varepsilon_{s} g_{o}}{41-33 \eta}\right)+\frac{512 \varepsilon^{2} \eta g_{o}}{25 \pi}\right\}$

Granular energy dissipation (Lun et al. 1984)

$\gamma_{s}=\frac{48 \rho_{s} \varepsilon_{s}^{2} g_{o}}{\sqrt{\pi}} \eta(1-\eta) \theta^{3 / 2}$

Radial distribution function (Ding and Gidaspow, 1990)

$g_{o}=\left[1-\left(\frac{\varepsilon_{s}}{\varepsilon_{s, \max }}\right)^{\frac{1}{3}}\right]^{-1}$

Table 2. Parameters used in the simulation

\begin{tabular}{l|l}
\hline Particle material & Glass ballotini \\
Fluidizing gas & Air at ambient condition \\
Mean particle diameter & $200 \mu \mathrm{m}$ \\
Particle density & $2500 \mathrm{~kg} \mathrm{~m}^{-3}$ \\
Bottom bed width & $0.1 \mathrm{~m}$ \\
Total bed height & $0.46 \mathrm{~m}$ \\
Static bed height & $0.03 \mathrm{~m}$ \\
Inlet superficial gas velocity & $0.83,0.97,1.1 \mathrm{~m} \mathrm{~s}^{-1}$ \\
Nozzle air velocity & $20 \mathrm{~m} \mathrm{~s}^{-1}$ \\
Restitution coefficient & $0.9(-)$ \\
Packing limit & $0.6(-)$ \\
Angle of internal friction & $25^{\circ}$ \\
\hline
\end{tabular}

Table 3. Parameters used in the droplet-granule calculation.

\begin{tabular}{l|llllllll}
\hline Parameter & $D$ & $\rho_{L}$ & $d_{s}$ & $\theta$ & $g_{0}$ & $\varepsilon_{s}$ & $\phi$ & $\dot{M}_{D}$ \\
& $(\mu \mathrm{m})$ & $\left(\mathrm{kg} \mathrm{m}^{-3}\right)$ & $(\mu \mathrm{m})$ & $\left(\mathrm{m}^{2} \mathrm{~s}^{-2}\right)$ & $(-)$ & $(-)$ & $(\mathrm{rad})$ & $\left(\mathrm{g} \mathrm{s}^{-1}\right)$ \\
\hline Value & 40 & 1093 & 200 & 0.01 & 1.63 & 0.04 & $\pi / 8$ & 0.133 \\
\hline
\end{tabular}

